\title{
Infective endocarditis as a cause of severe mitral regurgitation: a case report
}

\author{
(i)Ivana Lukić', \\ (DKristina Vučković', \\ (D)Marko Stupin ${ }^{1,2}$, \\ (DLana Maričićc ${ }^{1,2}$, \\ (i) Kristina Selthofer- \\ Relatić1,2, \\ (1) Sandra Makarović1,2* \\ 'University Hospital Centre \\ Osijek, Osijek, Croatia \\ ${ }^{2} \mathrm{School}$ of Medicine Osijek, \\ Croatia
}

KEYWORDS: endocarditis, mitral valve prolapse, mitral valve replacement. CITATION: Cardiol Croat. 2018;13(5-6):188. | https://doi.org/10.15836/ccar2018.188

*ADDRESS FOR CORRESPONDENCE: Sandra Makarović, Klinički bolnički centar Osijek, J. Huttlera 4, HR-31000 Osijek, Croatia. / E-mail: sandramakarovic@yahoo.com

ORCID: Ivana Lukić, https://orcid.org/0000-0001-9832-6700 • Kristina Vučković, https://orcid.org/0000-0001-5096-2601 Marko Stupin, https://orcid.org/0000-0001-7296-1669 • Lana Maričić, https://orcid.org/0000-0001-6035-6760

Kristina Selthofer-Relatić, https://orcid.org/0000-0002-9890-6489 • Sandra Makarović, https://orcid.org/0000-0002-7487-1189

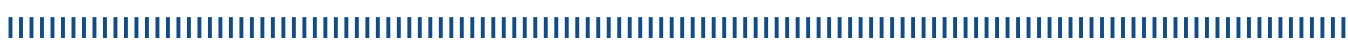

Introduction: Infective endocarditis is an acute condition with very high mortality. It is typically a bacterial infection and often affects heart valves. Duke criteria which should be fulfilled to establish the diagnosis of endocarditis, rely on echocardiography ${ }^{1}$.

Case report 1: 63-year-old patient with history of posterior mitral valve prolapse and, consequently, a severe mitral insufficiency, for which an operational treatment is planned, was hospitalized at the Clinic for Infectious Diseases for fever with characteristic features of sepsis. Staphylococcus aureus was isolated from blood culture and there was a suspicion of insufficient mitral valve endocarditis. A transthoracic ultrasound of heart was done and a mass which seemed to be vegetation on the prolapsed back mitral valve was verified and confirmed by a transesophageal echocardiography. The patient was treated parenterally with antibiotics according to the antibiogram, after which a clinical improvement followed. After the improvement of the inflammation and the preoperative treatment, the patient was subjected to cardiac surgical replacement of the mitral valve with a mechanical prosthesis.

Case report 2: 58-year-old male patient was admitted to emergency room with severe pulmonary edema, fever, respiratory insufficiency and sepsis. Four months before, mitral valve was replaced by mechanical prostheses because of severe primary mitral regurgitation. A transthoracic echocardiogram showed prolapse of posterior cusp in left atrium and severe eccentric mitral regurgitation without clear vegetation on prosthetic mitral valve. Empirical antibiotic therapy was immediately started. Urgent reimplantation of mechanical mitral valve was done by the cardiac surgery team. Intraoperative mitral valve analysis showed a suture dehiscence of the prosthetic mechanical mitral valve. Microbiological samples and blood culture were sterile. During the postoperative monitoring, atrial fibrillation with total atrioventricular block was founded, and cardiac pacemaker was implanted.

Conclusion: We presented endocarditis based on prolapse of mitral valve and endocarditis of artificial mechanical mitral valve. In both cases a surgical replacement of mitral valve was performed, while in second case urgent surgery was done.

\section{RECEIVED:}

May 8, 2018

ACCEPTED:

May 10, 2018

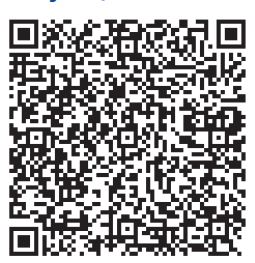

$\square$ Cardiologia Croatica 2018;13(5-6):188.

1. Habib G, Lancellotti P, Antunes MJ, Bongiorni MG, Casalta JP, Del Zotti F, et al; ESC Scientific Document Group. 2015 ESC Guidelines for the management of infective endocarditis: The Task Force for the Management of Infective Endocarditis of the European Society of Cardiology (ESC). Endorsed by: European Association for Cardio-Thoracic Surgery (EACTS), the European Association of Nuclear Medicine (EANM). Eur Heart J. 2015 Nov 21;36(44):3075-3128. https://doi.org/10.1093/eurheartj/ehv319 